aspects, in the congested, corymbose, and confluent forms; the confluent form being produced by the union, by congestion and infiltration, of the interfollicular portions of the skin. In the papulous eczemas, the presence of papules was the chief mark, but the other characteristic features might be present-e.g., infiltration and crusting, or fissures exuding ichor, when what was called by Willan lichen agrius was present. The polymorphic form and the tendency to exudation marked the latter condition as not different from eczema. Attention was next directed to several models of eczema nummulare, and $\mathrm{E}$. papulosum circumscriptum. The lecturer remarked that the development of the papules in groups was according to law, and took place under the influence of the nerves. He further observed that if it were said the various terms used to designate the several varieties of eczema were of no practical import, it might be replied that dermatologists are observing nature, and need scientific designations: whilst they reminded us that the same eruption was modified by locality, constitutional condition, and other circumstances, and their employment prevented us from error in diagnosis, enabling us to observe the relations of diseases that might otherwise be regarded as distinct affections, as in the cases of eczema exfoliativum and lichen agrius. The Willanean type of eczema vesiculosum was next described, and the difference between dry and moist eczemas accounted for by the presence or absence of odema, the latter giving rise to the outpouring of fluid with resiculation, or free oozing from an abraded surface. In the young, and the lymphatic, fluid exudation was observed; in the old, and subjects deficient in fluids, the eczema was of the dry variety. There is nothing specific in the vesiculation or the discharge of eczema, it was contended. The doctrine Mr. Wilson wished to impress on his hearers was that eczema is a simple inflammation of the skin, with variety in its manifestations, due to pecnliarity of structure of the surface, constitution of the patient, and duration of the disease; that it might consist of hyperæmia, and exfoliation or ichoration and incrustation in addition, in consequence of the occurrence of exudation. Hence there were two main forms, moist and dry. The hyperxmia might affect the papillary plexus or the follicular plexus or both; it disturbed the nutrition, hence the exfoliation of cuticle. If exudation occurred the cuticle was raised into resiculation, or there might be free oozing or abundant discharge of fluid of different characters, serous or purulent. The word "catarrhal" had been applied to eczema, which had been called catarrh of the skin, and this designation was no doubt correct. Lastly, Mr. Wilson gave a description of eczema squamosum, and pointed out that in chronic eczema of this kind the appearances of eczema erythematosum orbiculare and circinatum could be readily discerned in many cases.

The excellent models of the Dermatological Musenm, and coloured enlarged drawings used in illustration by the lecturer, were all that could be desired to give due effect to his verbal description.

\section{MEDICAL REPORT OF THE SMALL-POX AND VACCINATION HOSPITAL FOR 1870}

Presented to the Anmual Goneral Court of the Governors, held on Friday, Febriary 3rd, 1871.

The year 1870 will be memorable in the medical history of the nineteenth century. It has been marked by an epidemic of small-pox of peculiar severity, which has found the population of this metropolis very inadequately protected by vaccination; and, therefore, but little prepared for such a visitation. A much larger proportion of the population has been attacked by small-pox in the course of the existing epidemic than has ever occurred in the memory of the present generation. The epidemic of smallpox continues, and is extending. Each succeeding week it becomes more widely diffused, and the number of persons attacked is greater.

Small-pox was epidemic in London during the whole of 1870. Judging from the monthly admissions of patients into the Small-pox Hospital, the opidemic may be assumed to have commenced in November, 1869 . The rise and in- crease of the epidemic, during at least a portion of its course, will be shown by the monthly admissions into the Small-pox Hospital. For the last three or four months of the year, however, our admissions give no adequate idea of the prevalence of small-pox. Owing to the crowded state of our wards during the months of October, November, and December, large numbers of applicants bave of necessity been refused admission; and although additional hospitals have been opened in various parts of the metropolis, and the accommodation for small-pox patients has been enormously increased, it has been found insufficient to meet the requirements of the epidemic. The minimum of admissions into the Small-pox Hospital in 1869 was in the month of August, when they were only twenty-eight. At that time small-pox was sporadic only, and epidemic influence had not yet come into operation; it may serve, therefore, for a standard of comparison with the months that follow.

The monthly admissions of patients into the Small-pox and Vaccination Hospital have been as follows:-August, 1869 , 28; September, 31; October, 34; November, 51 December, 52 ; January (1870), 79 ; February, 66; March, 73; April, 83; May, 112; June, 112; July, 113; August, 89 ; September, 108 ; October, 144; November, 159 ; December, 178.

In the year 1870,1316 patients were admitted into the Small-pox Hospital. Of these, 1285 were suffering from small-pox, and 31 from various forms of eruptive or febrile disease, not small-pox, but assumed to be so, and on such assumption sent to the Small-pox Hospital. Of these 31 cases, 3 died. Of the 1285 cases of small-pox, 962 , or 74.9 per cent. of the whole cases, had been vaccinated, and 322 were unvaccinated. One patient was said to have had small-pox previously, and that case recovered. Of the 962 vaccinated cases, 76 died, giving a mortality of 7.9 per cent.; whilst of the 322 unvaccinated cases, 124 died, being a mortality of 38.5 per cent. Six of the doaths, 5 in the vaccinated and 1 in the unvaccinated class, were due to gangrene or some other form of superadded disease. Upwards of 30 patients admitted last year are still in the hospital, and of these several are in great danger.

The general mortality for the year 1870 has been 15.4 per cent. The high death-rate of the last year was due in part to the unusual severity or malignancy of the disease, and in part to the number of children suffering from small-pox who have been received into the hospital. Ten years sincenamely, in $1860-7 \cdot 37$ per cent. only of the whole admissions were children under ten years of age. As will be anticipated, the greater proportion of these were unvaccinated, and amongst them the mortality was 33.8 per cent. In 1870 more than 16 per cent. of the whole admissions were children under ten years of age, and the mortality amongst those of them who were unvaccinated was as high as 42 per cent.

Not a single fact has occurred within our experience at the hospital during the past year to shake our confidence in vaccination when properly performed, or to detract in any degree from that high estimate of its value which many years' experience in the wards of the hospital and a close study of small-pox have led us to form. But vaccination is an operation of considerable delicacy, and requires much care in order to secure the advantageous results it is capable of imparting. The failures of vaccination to prevent fatal small-pox which have occurred are almost all of them due to the careless and imperfect manner in which it has been practised.

In the present'state of the population revaccination is of scarcely less importance to the adult than is primary vaccination to the infant. A very large number of the adult population of this country are without adequate protection from vaccination, and are liable to take small-pox in its gravest and most deadly form. All persons who have not already had small-pox, and have been or are likely to be exposed to the infection of that disease, and all who have not several (at least four) good marks testifying to the character and efficiency of the primary vaccination, ought to be revaccinated. Revaccination has proved itself to be a most important and efficient means of preventing smallpox. For upwards of thirty years all the nurses and servants at the Small-pox Hospital who had not previously had small-pox have been revaccinated before entering on their respective duties, and in no one instance has it failed to preserve them from small-pox. We believe, therefore, 
that revaccination extensively practised, and with the same precautions to ensure efficiency as ought to be observed in primary vaccinations, will prove to be the most certain mode that could be adopted of checking the present epidemic of small-pox.

Three hundred and sixty persons have been vaccinated at the hospital during the year, and 580 charges of vaccine lymph have been supplied to the medical profession at home and abroad.

\section{Wilitam Munk, M.D., F.S.A., Physician to the Hospital. \\ J. F. MARSON, F.R.C.S., Surgeon to the Hospital.}

\section{THE NEW CONVALESCENT SMALL-POX HOSPITAL IN MARYLEBONE.}

ON Monday last a new iron hospital, erected on the St. Marylebone parochial stone-yard, was opened for the reception of convalescent cases of small-pox. The building is constructed of corrugated galvanised iron, and lined throughout with match boarding. Between the iron and the boarding the whole of the roof is covered with inodorous felt, which adds materially to the warmth of the building, and deadens the noise of the rain falling on the roof, which has in similar buildings been a source of great discomfort to patients. The building, which cost 300 guineas, and was completed within the extraordinarily short time of five days by Mr. Kent, the contractor, is well ventilated by windows placed opposite to each other and by openings in the roof, and the admission of air admits of being properly regulated. A stove is placed in the centre of each ward, by means of which a temperature of $60^{\circ} \mathrm{F}$. can be obtained, and maintained even in the coldest weather. The amount of space contained in the building is 35,000 cubic feet, which will give to twenty-six patients (the number which Dr. Whitmore purposes to admit) about 1400 cubic feet each.

Dr. Whitmore has considerately supplied for each patient a comfortable hospital suit. The beds and bedding are excellent of their kind, and the whole aspect of the building is one of great comfort and cheerfulness.

The Vestry, under whose sanction and authority the building has been erected, are entitled to credit for the prompt provision which they have made to meet the emergencies created by the outbreak of the present epidemic, and the readiness with which they have seconded the efforts of Dr. Whitmore, under whose personal control and direction the new building has been erected.

\section{Cortespondente.}

$$
\text { "Audi alteram partem." }
$$

\section{CAN THE DEAD CONVEY INFECTION?}

To the Editor of THE LANCET.

Str,-Dr. Wilks's letter in your last number, relative to the carriage of infection by the dead, in which he states his opinion, "framed from negative evidence, that all fear from contagion ceases with death," induces me to call atten. tion to what took place many years ago at the Anatomical School in Great Windmill-street, and leads me to abstain from sending the bodies of those who die of small-pox to the Schools of Anatomy. The history of what ocourred will be found in a letter from Mr. Cæsar Hawkins, in volume iii., page 282, of The London MLedical Gazette for January 31st, 1829. It is briefly as follows:- "A body of a man was brought to the School in Great Windmill-street, who appeared to have died of confluent small-pox. It was injected with the usual saline solution, and kept in an outer room for some days, when it was taken into the dissecting room for about two hours on two successive days. "For about ten days, therefore," says Mr. Hawkins, "it might have been possible for the contagion of small-pox to be exerted, which probably was the case, as within a short time four gentlemen have gone through the disease." One of them merely saw the body without approaching near it, but it excited a great feeling of disgust at the time; another went near it, but did not actually touch it; a third had been in the habit of frequenting the Small-pox Hospital and making drawings of the disease as short a time as three months before he actually received the disorder; a fourth had touched it with his hands. Three of these gentlemen had the disease mildly ; the fourth had it in a rather severe form ; he had been vaccinated and had a good cicatrix.

I take the liberty of recommending that Mr. Hawkins's communication be read before it is decided "that all fear of infection ceases with death."

I am, Sir, your obedient servant,

Savile-row, February 7 th, 1871.

Charles Hawrins.

\section{To the Editor of The LaNCET.}

SIR,-In reply to Dr. Wilks's letter on this subject in THE. LANCET of last week, I beg leave to inform you that in the spring of 1838 four students of the London Hospital, including my brother and myself, took small-pox from a subject brought into the rooms. For myself, I had no fear of infection or contagion, and no expectation that dissection would be attended with so unpleasant a result. I had no punctured wound, and was not exposed to any other source of infection that I was aware of.

To those who adrocate the plan of vaccinating in a multiplicity of places, it may not be amiss to remark that I have two vaccination marks, and two only, still distinctly visible, placed where they ought to be, one a little above the insertion of the deltoid muscle in each arm, and that these two places of vaccination sufficed to secure to me a modified and mild attack of the disease.

The prejudice and objections which still prevail against vaccination arise from (1) the uncertainty of its protective influence, and (2) from the occurrence of undesirable sequelæ both in the form of unnecessary disfigurement and of deterioration of health. The uncertain protection of vaccination ought always to be proved by revaccination, and by Bryce's test if practicable.

The place vaccinated should always be carefully selected, especially in girls, and especial care should be taken to vaccinate with lymph from a normal vesicle, on the 5th, 6 th, or 7 th day, before the lymph has become in any degree purulent. Some infants undoubtedly suffer much from vaccination, and become deteriorated in health. In such cases I have given from ten to twenty drops of brandy, or, better still, of compound tincture of cardamoms, twice or three times a day for a few days, with decided benefit.

Lastly, it has occurred to me that the judicious exhibition of coloured drawings or photographs of the very loathsome disease that small-pox is, would do more to remove existing objections to vaccination than many proclamations and Acts of Parliament. People see and feel the minor evil of vaccination, but the large majority are ignorant of the greater evil of small-pox; and do not readily comprehend how the lesser evil, which they do see, can avail against. the greater evil which they have never seen. I am, Sir, your obedient servant,

Five Houses, Clapton, Feb. 4th, 1871

$$
\text { D. De Berdt Hover. }
$$

\section{THE EMPLOYMENT OF MERCURY IN HEPATIO: DISEASES.}

To the Editor of THE LANCET.

SIe,-It is not my intention to interfere in the contro versy that has arisen between Professor Bennett and. Deputy Inspector-General Rutherford, C.B., further than to give certain explanations which seem required at $\mathrm{my}$ hands.

1. Dr. Bennett has been led into grave error by a false statement on the part of the discharged soldier, Nicholas H- to the effect that when he was a patient in the Royal Victoria Hospital in 1867, "the ointment of the biniodide of mercury was rubbed over his liver twice daily for two weeks." Dr. Bennett has seen fit to repeat this 